\title{
In Vivo Targeting Replication Protein A for Cancer Therapy
}

\author{
Pamela S. VanderVere-Carozza ${ }^{1}$, Navnath S. Gavande ${ }^{1,2}$, Shadia I. Jalal ${ }^{1}$, \\ Karen E. Pollok ${ }^{3}$, Elmira Ekinci ${ }^{4}$, Joshua Heyza ${ }^{4}$, Steve M. Patrick ${ }^{4}$, Andi Masters ${ }^{5}$, \\ John J. Turchi ${ }^{1,6 *}$ and Katherine S. Pawelczak ${ }^{6 *}$

\begin{abstract}
1 Department of Medicine, Indiana University School of Medicine, Indianapolis, IN, United States, ${ }^{2}$ Department of Pharmaceutical Sciences, Wayne State University College of Pharmacy and Health Sciences, Detroit, MI, United States, ${ }^{3}$ Herman B. Wells Center for Pediatric Research, Departments of Pediatrics, Pharmacology and Toxicology, Medical and Molecular Genetics Indiana University Simon Comprehensive Cancer Center, Indianapolis, IN, United States, ${ }^{4}$ Department of Oncology, Wayne State University School of Medicine and Barbara Ann Karmanos Cancer Institute, Detroit, MI, United States, ${ }^{5}$ Indiana University Cancer Center, Indiana University School of Medicine, Indianapolis, IN, United States, ${ }^{6}$ NERx BioSciences, Indianapolis, IN, United States
\end{abstract}

\section{OPEN ACCESS}

Edited by:

Shoumin Zhu,

University of Miami Health System,

United States

Reviewed by:

Lei Chen,

Capital Medical University, China Alvaro Galli,

Pisa Research Area (CNR), Italy Jac Nickoloff,

Colorado State University, United States

*Correspondence: John J. Turchi jturchi@iu.edu

Katherine S. Pawelczak

kspawelczak@NERxbiosciences.com

Specialty section: This article was submitted to

Cancer Molecular Targets and Therapeutics,

a section of the journal

Frontiers in Oncology

Received: 01 December 2021 Accepted: 18 January 2022 Published: 18 February 2022

Citation:

VanderVere-Carozza PS, Gavande NS, Jalal SI, Pollok KE, Ekinci E, Heyza J, Patrick SM,

Masters A, Turchi JJ and

Pawelczak KS (2022) In Vivo Targeting Replication Protein A for Cancer Therapy.

Front. Oncol. 12:826655. doi: 10.3389/fonc.2022.826655
Replication protein A (RPA) plays essential roles in DNA replication, repair, recombination, and the DNA damage response (DDR). Retrospective analysis of lung cancer patient data demonstrates high RPA expression as a negative prognostic biomarker for overall survival in smoking-related lung cancers. Similarly, relative expression of RPA is a predictive marker for response to chemotherapy. These observations are consistent with the increase in RPA expression serving as an adaptive mechanism that allows tolerance of the genotoxic stress resulting from carcinogen exposure. We have developed secondgeneration RPA inhibitors (RPAis) that block the RPA-DNA interaction and optimized formulation for in vivo analyses. Data demonstrate that unlike first-generation RPAis, second-generation molecules show increased cellular permeability and induce cell death via apoptosis. Second-generation RPAis elicit single-agent in vitro anticancer activity across a broad spectrum of cancers, and the cellular response suggests existence of a threshold before chemical RPA exhaustion induces cell death. Chemical RPA inhibition potentiates the anticancer activity of a series of DDR inhibitors and traditional DNAdamaging cancer therapeutics. Consistent with chemical RPA exhaustion, we demonstrate that the effects of RPAi on replication fork dynamics are similar to other known DDR inhibitors. An optimized formulation of RPAi NERx 329 was developed that resulted in single-agent anticancer activity in two non-small cell lung cancer models. These data demonstrate a unique mechanism of action of RPAis eliciting a state of chemical RPA exhaustion and suggest they will provide an effective therapeutic option for difficult-totreat lung cancers.

Keywords: DNA repair inhibitors, Replication Stress Response, Replication Protein A, DNA damage response, DNA repair and cancer 


\section{INTRODUCTION}

The DNA damage response (DDR) is composed of a complex network of DNA repair and cell signaling pathways that are critical toward maintaining genomic stability. Dysfunctional DDR causes damage to the genome that results in genomic instability, providing a selective advantage over normal cells and enabling rampant proliferation and survival. This genomic instability frequently arises from mutations of certain cell cycle and DDR genes, which in turn creates an increased dependency on other components of the DDR network. This reliance on specific DDR machinery can make cancer cells more vulnerable to therapies targeting DDR components. Certain drugs, like the popular poly (ADP-ribose) polymerase (PARP) inhibitors, can take advantage of targeting cancers with specific known DDR mutations and can impart therapeutic benefit through a synthetic lethality approach (1). Recent evidence also suggests that the DDR is involved in activation of the innate immune response, suggesting that DDR inhibitors combined with immunotherapy may have anticancer activity (2). Other agents targeting specific DDR signaling molecules have shown singleagent and combination activity (3).

Oncogenic replication stress (RS) coupled with DDR blockade results in local effects at the replication fork and global effects on cell cycle and signaling that ultimately result in replication catastrophe (RC) and cell death. The human single-stranded DNA (ssDNA) binding protein, replication protein A (RPA), is a critical regulator of the DDR, with depletion of active RPA or "RPA exhaustion" driving RC and cell death. RPA is the major eukaryotic ssDNA binding protein, and its level and activity are tightly regulated. High levels of ssDNA resulting from DDR inhibition can exhaust cellular RPA such that there is insufficient RPA-DNA binding capacity to engage all the ssDNA generated. The lack of RPA available to protect ssDNA then renders DNA susceptible to digestion by nucleases resulting in DNA strand breaks at replication forks, $\mathrm{RC}$, and cell death $(4,5)$. We have targeted this crucial DNA metabolic pathway required for genome stability and maintenance via small molecule inhibitors (SMIs) that block the RPA-DNA interaction.

First-generation RPA inhibitors (RPAis) were developed and have been extensively characterized with respect to potency and mechanism of action (6-8). Predecessor RPAi TDRL-551 (551) displays in vivo activity in lung cancer xenograft models. In an effort to determine if lowering the RPA threshold with $\mathbf{5 5 1}$ would result in a synergy with DNA-damaging agents like platinum (Pt)-based drugs, in vivo efficacy studies were performed in nonsmall cell lung cancer (NSCLC) xenograft models. Combinatorial experiments with $\mathrm{Pt}$ were conducted with a reduction of both carboplatin and $\mathbf{5 5 1}$ doses to ensure a window to observe potential synergy. Single-agent activity was observed, as well as a greater than additive effect on tumor growth delay with the carboplatin-551 combination compared to each agent alone. In addition, 551 displays in vitro, cellular, and in vivo anticancer activity and synergy with cisplatin. Despite the effectiveness of 551 in preclinical studies, certain chemical moieties of the molecule represented chemical liabilities for clinical readiness of the drug. A series of second-generation inhibitors was generated and optimized for solubility, stability, and cellular uptake (9). A morpholino derivative, NERx 329 (329), demonstrated enhanced solubility and cellular uptake with superior physicochemical properties. The chemical modifications resulting in ideal drug-like characteristics in the 329 molecule are expected to vastly improve cellular potency, the in vivo anticancer activity, and general clinical readiness of the drug. Here, we report the cellular effects and in vivo studies completed with $\mathbf{3 2 9}$ and introduce a novel formulation strategy that dramatically improves bioavailability of $\mathbf{3 2 9}$.

\section{MATERIALS AND METHODS}

\section{Replication Protein A Inhibitors}

RPAis 329 and 2004 were synthesized and characterized as previously described (9).

\section{Electrophoretic Mobility Shift Assay (EMSA)}

EMSAs were performed as previously described (9). Briefly, reactions were conducted in $20 \mathrm{mM}$ HEPES ( $\mathrm{pH} 7.8$ ), $1 \mathrm{mM}$ DTT, $0.001 \% \mathrm{NP}-40$, and $50 \mathrm{mM} \mathrm{NaCl}$. RPAis were suspended in $100 \%$ dimethlysulfoxide (DMSO), and DMSO concentration in the final reaction mixture was constant at less than $5 \%$. Purified full-length RPA (120 ng) was incubated with the indicated RPAi or vehicle in reaction buffer for $30 \mathrm{~min}$ before the addition of the $\left[{ }^{32}\right] \mathrm{P}$-labeled 34 -base ssDNA probe. Reactions were incubated for $5 \mathrm{~min}$ at room temperature, and products were separated via $6 \%$ native polyacrylamide gel electrophoresis. The bound and unbound fractions were quantified by phosphorimager analysis using ImageQuant software (Molecular Dynamics, CA), and data were fit by non-linear regression using GraphPad Prism.

\section{CCK-8 Viability Assays}

Cell lines were obtained from ATCC and maintained as monolayer cultures in RPMI 1640 medium $(\mathrm{H} 460)$ or Dulbecco's Modified Eagle's Medium (DMEM) (A549) supplemented with $10 \%$ fetal bovine serum. H460 and A549 cells were plated at $2.5 \times 10^{3}$ cells/well and A2780 and GCT27 cells plated at $5 \times 10^{3}$ cells/well in a 96-well plate and incubated for 18-24 h prior to treatments. Cells were treated with the indicated concentration of RPAi for $48 \mathrm{~h}$. The vehicle (DMSO) concentration was held constant at $1 \%$. Cell metabolism/viability was assessed by a mitochondrial metabolism assay (CCK-8) as we have described previously (10). The generation of the watersoluble formazan product by cellular dehydrogenases is proportional to the number of living cells. Following incubation with CCK-8 reagent, absorbance was measured at $450 \mathrm{~nm}$ with a BioTek Synergy H1 plate reader. Values were compared to those of vehicle-treated controls to determine percent viability, and the results represent the average and SEM of triplicate determinations. 


\section{Apoptosis Assay}

Apoptosis induction was determined by activation of Caspases 3 and 7 using the CellEvent ${ }^{\mathrm{TM}}$ Caspase-3/7 Green Detection Reagent (Invitrogen). H460 cells were plated at $5 \times 10^{3}$ cells/ well in black 96-well plates with clear bottoms (Costar) and incubated for $24 \mathrm{~h}$ prior to treatments. Cells were treated with the indicated concentration of RPAi or cisplatin for $24 \mathrm{~h}$. The vehicle (DMSO) concentration was held constant at $1 \%$ for RPAi treatments. For caspase 3/7 detection, medium was removed and replaced with phosphate buffered saline (PBS) containing $5 \%$ fetal bovine serum (FBS) and $2 \mu \mathrm{M}$ CellEvent ${ }^{\mathrm{TM}}$ Caspase-3/7 Green Detection Reagent. Cells were incubated at $37^{\circ} \mathrm{C} / 5 \% \mathrm{CO}_{2}$ for $1 \mathrm{~h}$, and fluorescence intensity was measured in a BioTek Synergy H1 plate reader (excitation/emission 485/528). Images were captured with an Evos FL2 Auto microscope (Invitrogen) using a $10 \times$ objective.

\section{Cell Viability in 60 Cancer Cell Lines}

In this study, 90- $\mu$ l cell suspensions were seeded in 96-well plates in respective culture medium with a final cell density of $4 \times 10^{3}$ cells/well and incubated overnight. Here, 10× solution of 329 (top working concentration: $40 \mu \mathrm{M}$ of test article in media with 3.16-fold serial dilutions to achieve 9 dose levels) was prepared, and $10 \mu \mathrm{l}$ of drug solution or culture medium containing $0.5 \%$ DMSO (vehicle control) was added to the plate (triplicate for each drug concentration). Plates were incubated for $72 \mathrm{~h}$ at $37^{\circ} \mathrm{C}$ with $5 \% \mathrm{CO}_{2}$ and then measured by CellTiter-Glo assay (Promega). Briefly, plates were equilibrated at room temperature for $30 \mathrm{~min}$, and $50 \mu \mathrm{l}$ of CellTiter-Glo reagent was added to each well. Contents were mixed for $5 \mathrm{~min}$ on an orbital shaker to induce cell lysis, and plates were further incubated at room temperature for $20 \mathrm{~min}$ to stabilize the luminescent signal. Luminescence was recorded using EnVision Multi Plate Reader. Percent cell growth was calculated relative to DMSO-treated cells (vehicle control), and the data were fit using non-linear regression analysis (GraphPad PRISM) to calculate cellular $\mathrm{IC}_{50}$.

\section{DNA Fiber Analysis}

Analysis of DNA replication intermediates was performed as previously described with minor modifications $(11,12)$. H460 cells were seeded in 6 -well plates at a density of $2 \times 10^{5}$ cells. The following day, cells were labeled with iodo-deoxyuridine (IdU) $(20 \mu \mathrm{M})$ for $20 \mathrm{~min}$, followed by treatment with hydroxyurea (HU) $(2.5 \mathrm{mM})$ for $60 \mathrm{~min}$, then released into chlorodeoxyuridine (CldU) $(200 \mu \mathrm{M})$ for $20 \mathrm{~min}$, followed by treatment with ATR inhibitor (ATRi) VE-822 (2 $\mu \mathrm{M}$, Selleckchem, S8807) for $2 \mathrm{~h}$ or RPAi $329(50 \mu \mathrm{M})$ for $2 \mathrm{~h}$. After harvesting, the cells were resuspended in PBS at a concentration of $1,000,000 \mathrm{cells} / \mathrm{ml}$, and $2 \mu \mathrm{l}$ of the cell suspension was mixed with $8 \mu \mathrm{l}$ of lysis buffer $(200 \mathrm{mM}$ Tris$\mathrm{HCl} \mathrm{pH} \mathrm{7.5,} 50 \mathrm{mM}$ EDTA, 0.5\% SDS) on a Superfrost Plus microscope slide (Fisher Scientific). After $6 \mathrm{~min}$ of incubation, the slides were tilted at a 45-degree angle to allow cell lysates to slowly run down the slide. After air-drying, the slides were fixed in methanol:acetic acid (3:1) and stored at $4^{\circ} \mathrm{C}$. DNA fibers were denatured with $2.5 \mathrm{~N} \mathrm{HCl}$ for $1 \mathrm{~h}$, washed with PBS, and blocked with $5 \%$ BSA in PBS-T (PBS $+0.1 \%$ Tween-20) for $1 \mathrm{~h}$. DNA fibers were incubated with rat anti-BrdU antibody (1:50, Abcam, ab6326) for CldU and mouse anti-BrdU antibody (1:50, BD Biosciences, 347580) for IdU in a humid chamber at $37^{\circ} \mathrm{C}$ for $1 \mathrm{~h}$. After washing, slides were incubated with secondary antibodies anti-rat Alexa 488 (1:100) and anti-mouse Alexa 568 (1:100) at room temperature for $45 \mathrm{~min}$. Excess antibodies were removed by washing with PBS-T 3 times. After air-drying, the slides were mounted onto a coverslip with mounting medium. Fiber tracts were imaged with a Nikon epifluorescence microscope using a $40 \times$ oil immersion objective, and 100 fibers for each group were analyzed in ImageJ where the ratios of CldU : IdU were compared using pixel length. Data were analyzed by ANOVA with Bonferroni test for multiple comparisons.

\section{Combination Studies}

To assess synergy, the combination index (CI) was determined as described by Chou-Talalay as we have previously described (8). Briefly, H460 cells were treated with RPAi and the indicated agent alone and in combination. The range of treatment was dependent on the $\mathrm{IC}_{50}$ of each agent, and the range was $1 / 4$ to $3 \times$ $\mathrm{IC}_{50}$. The data from both the single-agent treatments and the combination treatment were used to calculate the CI and plot this value as a function of the fraction of cells affected (Fa). A CI of $>1$ indicates antagonism between the two agents, while a $\mathrm{CI}<1$ indicates synergy. A CI of 1 demonstrates an additive effect.

\section{Pharmacokinetics}

A method to quantify 329 from plasma has been developed using an internal standard, liquid-liquid extraction, and HPLC-MS/ MS. Mouse plasma samples were prepared from treated mice at the indicated times frozen at $-80^{\circ} \mathrm{C}$ until analysis. Plasma samples were thawed $(20 \mu \mathrm{l})$ and transferred to polypropylene tubes, and the internal standard is added $(20 \mu \mathrm{l}$ of $0.1 \mathrm{ng} / \mu \mathrm{l})$. Samples were diluted in $0.1 \mathrm{M}$ phosphate buffer $(\mathrm{pH}=7.4)$ and equal volume of methyl tertiary butyl ether. The samples were mixed and centrifuged at $12,000 \times \mathrm{g}$ for $5 \mathrm{~min}$, and the supernatant was transferred to a clean polypropylene tube. The solvent was evaporated to dryness, brought up in mobile phase analyzed by HPLC-MS/MS (ABSciex 4000). The mobile phase is delivered via gradient using acetonitrile and $0.1 \%$ formic acid on an Agilent Zorbax 300SB-C8 $150 \times 4.6 \mathrm{~mm}, 5-\mu \mathrm{m}$ column. The mass spectrometer utilized an electrospray ionization probe run in positive mode. Multiple reaction monitoring was employed with Q1/Q3 (m/z) transitions for 329 at 718.2/128.1 and 687.3/ 128.1 for the internal standard. The lower limit of quantification is $0.1 \mathrm{ng} / \mathrm{ml}$ using $20 \mu \mathrm{l}$ of plasma.

\section{In Vivo Analyses}

To assess anticancer efficacy, the hind flanks of 60 8-10-week-old Nod SCID gamma (NSG) mice were implanted with the indicated cells $\left(\sim 2 \times 10^{6}\right)$ in Matrigel. Tumor volumes were monitored by electronic caliper measurement [tumor volumes = length $\times$ (perpendicular width $\left.)^{2} \times 0.5\right]$. NSG studies were approved by the Institutional Animal Care and Use Committee at Indiana University School of Medicine. Male NSG (NOD- 
scid/IL2Rg ${ }^{\text {null }}$ ) mice (In Vivo Therapeutics Core Facility, IU Simon Comprehensive Cancer Center, Indianapolis, IN, USA) were used and housed in a pathogen-free facility at IUSM LARC. Mice with tumors of approximately $100 \mathrm{~mm}^{3}$ were randomized into individual treatment arms. The indicated RPAi was formulated and administered via intraperitoneal injection (IP) at the indicated times. Tumor volumes were monitored biweekly as indicated, and the results are presented as the average tumor volume \pm standard error of the mean for each group. The number $(\mathrm{n})$ for each experiment is presented in the figure legend.

\section{RESULTS}

\section{Retrospective Analysis of Replication Protein A Expression in Lung Cancer}

Considering the model of RPA exhaustion limiting the DDR to exogenous damage and replication stress, we sought to determine how the expression of RPA impacted survival in lung cancer. We selected lung cancer, as lung epithelial cells are continuously exposed to a wide array of potentially carcinogenic agents, a situation exacerbated by smoking and second-hand smoke exposure. To assess the potential clinical utility of RPA inhibition, we performed a retrospective analysis of gene expression data in lung cancer as a function of smoking history and response to chemotherapy treatment. In current and former smokers, the data reveal that high RPA expression is a negative prognostic biomarker correlating with worse overall survival (Figure 1A). This difference in survival as a function of RPA expression was also observed when selecting patients who received adjuvant chemotherapy that often includes Pt-based DNA-damaging agents (Figure 1B). These data demonstrate that low RPA expression is predictive of a better therapeutic response. In the analysis of never smokers (Figure 1C), no correlation between RPA expression and survival was observed. Importantly, this patient population is a collection of heterogeneous cancer phenotypes that is characterized by a higher level of driver mutations in growth signaling pathways, and as such, these never smokers are expected to have received targeted kinase inhibitor therapy. The finding that RPA expression level does not impact survival is therefore not surprising. Collectively, these data suggest that potential genotoxic damage induced by smoke exposure induces reliance on RPA expression to protect against genotoxic stress that, if reversed, could impact survival.

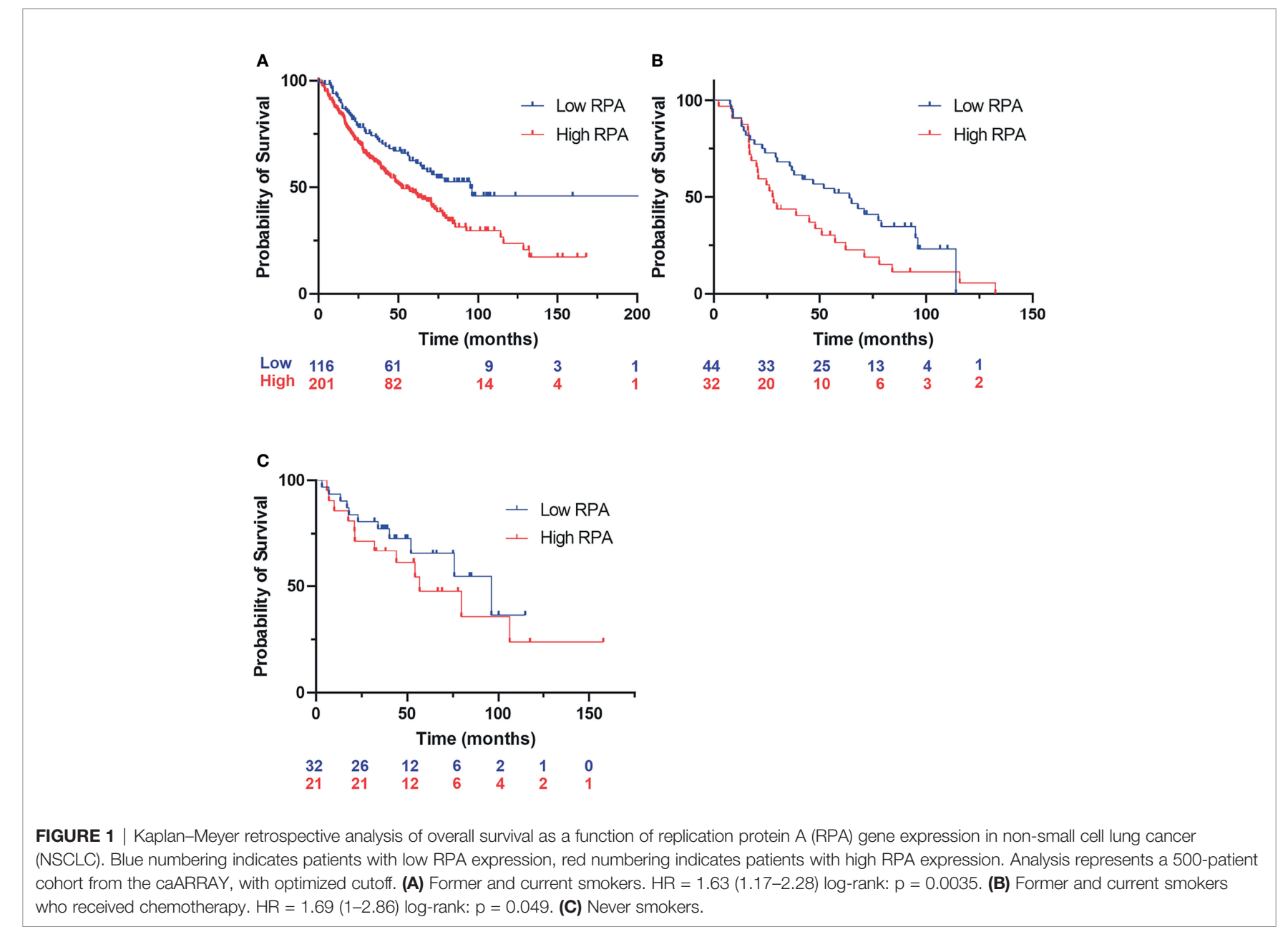




\section{Chemical Inhibition of Replication Protein A and Mechanisms of Cell Death}

Our previous analyses of reversible RPAis revealed both in vitro and in vivo activity, but chemical liabilities limited their broad utility in cell-based and in vivo assays $(6,8)$. We have further optimized the 551 candidate to generate candidate RPAi 329 and a derivative 2004 (Figure 2A) that possess potent RPA inhibitory activity in vitro, in vivo, and in cellular assays (Figures $\mathbf{2 B}, \mathbf{C}$ ). The data also show that the compounds are specific for inhibiting the RPA ssDNA interaction, as the interaction of Escherichia coli single strand binding protein (SSB) with ssDNA as indicated is not impacted by the RPAis. These compounds also display excellent solubility, cellular uptake, and physicochemical properties (9). As the addition of a propyl-morpholino to the oxopentoic acid moiety increased solubility and cellular uptake, we sought to assess single-agent cellular anticancer activity in the H460 NSCLC cell line (Figure 2C). The data demonstrate that 329 and 2004 possess potent single-agent activity compared to the $\mathbf{5 5 1}$ predecessor as assessed by CCK- 8 metabolic assay.

Predecessor reversible RPAis 505 and 551 also displayed single-agent anticancer activity, although this was not accompanied by caspase activation or annexin V/PI positivity, suggesting a non-apoptotic mechanism of cell death (6). The increased cellular uptake and potency displayed by the morpholino-containing compound 329 prompted us to revisit this activity. Using the activation of caspases 3 and 7 as a readout, we demonstrate that 329 induces cell death via a classical apoptotic pathway (Figure 3), and the activation of caspases 3
A

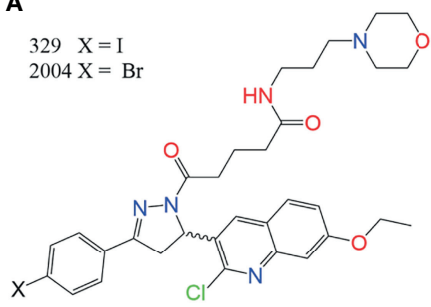

B

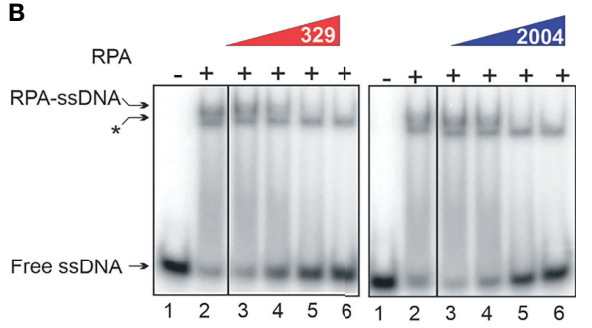

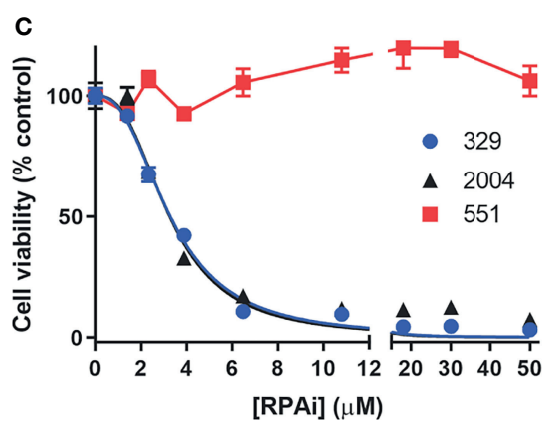

FIGURE 2 | Replication protein A inhibitor (RPAi) inhibitory activity. (A) Chemical structure of RPAi's 329 and 2004. (B) EMSA analysis of RPA-DNA interaction inhibition by 329 and 2004. Lanes 3-6 in each panel contain $6.25,12.5,25$, and $50 \mu \mathrm{M}$ of the indicated RPAi, respectively. The * indicates the position of the Escherichia coli SSB-singlestranded DNA (ssDNA) complex that serves as an internal specificity control. (C) Cell viability of H460 NSCLC cells in response to 329 and 2004.

A

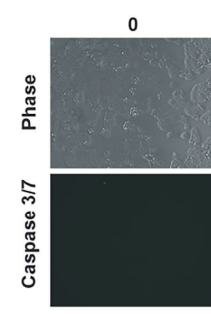

[329] $(\mu \mathrm{M})$

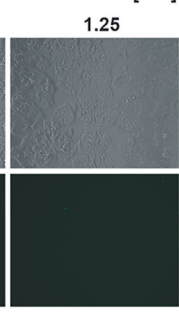

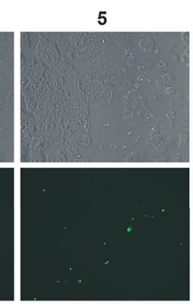

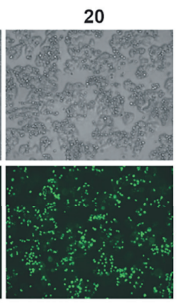

B

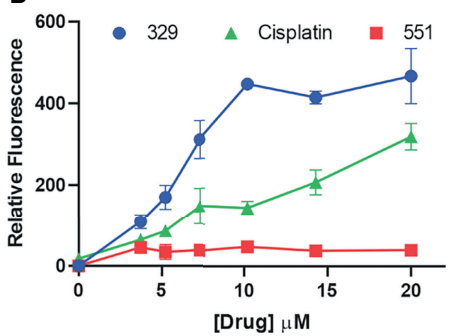

FIGURE 3 | The $\mathbf{3 2 9}$ induction of apoptotic cell death. (A) Analysis of caspase 3/7 activity in H460 cells following $24 \mathrm{~h}$ of treatment with $1 \%$ DMSO or the indicated concentrations of $\mathbf{3 2 9}$. Fluorescence images were captured as described in the Materials and Methods. (B) Quantification of caspase $3 / 7$ activity. Fluorescence was measured in 96-well plates using a Biotek Synergy H1 plate reader following 24-h incubation with the indicated drugs and concentrations. 
and 7 clearly distinguishes it from predecessor compound $\mathbf{5 5 1 .}$ Importantly, 551 does show decreased viability in clonogenic survival assays at the concentrations tested. The inability to detect caspase activity suggests that this is a distinguishing characteristic between the two (8). The titration analyses assessing apoptosis correlated with the corresponding CCK-8 viability curves and show the presence of a modest threshold. Assessment of apoptosis at $48 \mathrm{~h}$ was similar to $24 \mathrm{~h}$ in terms of the titration, though the maximum signal detected was higher, as expected.

Analyses of single-agent activity of compound 329 in 60 discrete cancer cell lines across a variety of solid tumors revealed similar findings. A range of $\mathrm{IC}_{50}$ values were obtained, with most falling between 5 and $10 \mu \mathrm{M}$ and largely independent of tumor site (Figure 4A). Certain uterine, lung, and esophageal cancer cell lines were the most sensitive, while pancreatic adenocarcinomas tended to be more resistant. Interestingly, the
Hill coefficients spanned a much larger range (Figure 4B), which did not necessarily correlate with the potency as measured by $\mathrm{IC}_{50}$. Certain lung, muscle, ovarian, and cervical cancer lines were characterized by the lowest Hill coefficients. These data are consistent with the tumor agnostic nature of RPA inhibition and a mechanism of action involving a threshold of measurable cytotoxic sensitivity.

A further measure of altered DDR induced by RPA inhibition is the degradation of replication forks upon stalling and RPA exhaustion. We therefore assessed replication fork dynamics and nascent strand degradation using DNA fiber analysis. The treatment scheme is depicted in Figure 5A. We first pulselabeled replicating DNA with IdU for $20 \mathrm{~min}$. After IdU removal, replication forks were stalled by the addition of HU or left to replicate with vehicle treatment. HU was removed and replication labeled with CldU. Then, CldU cells were treated with the DDRi or vehicle. The data obtained are presented in
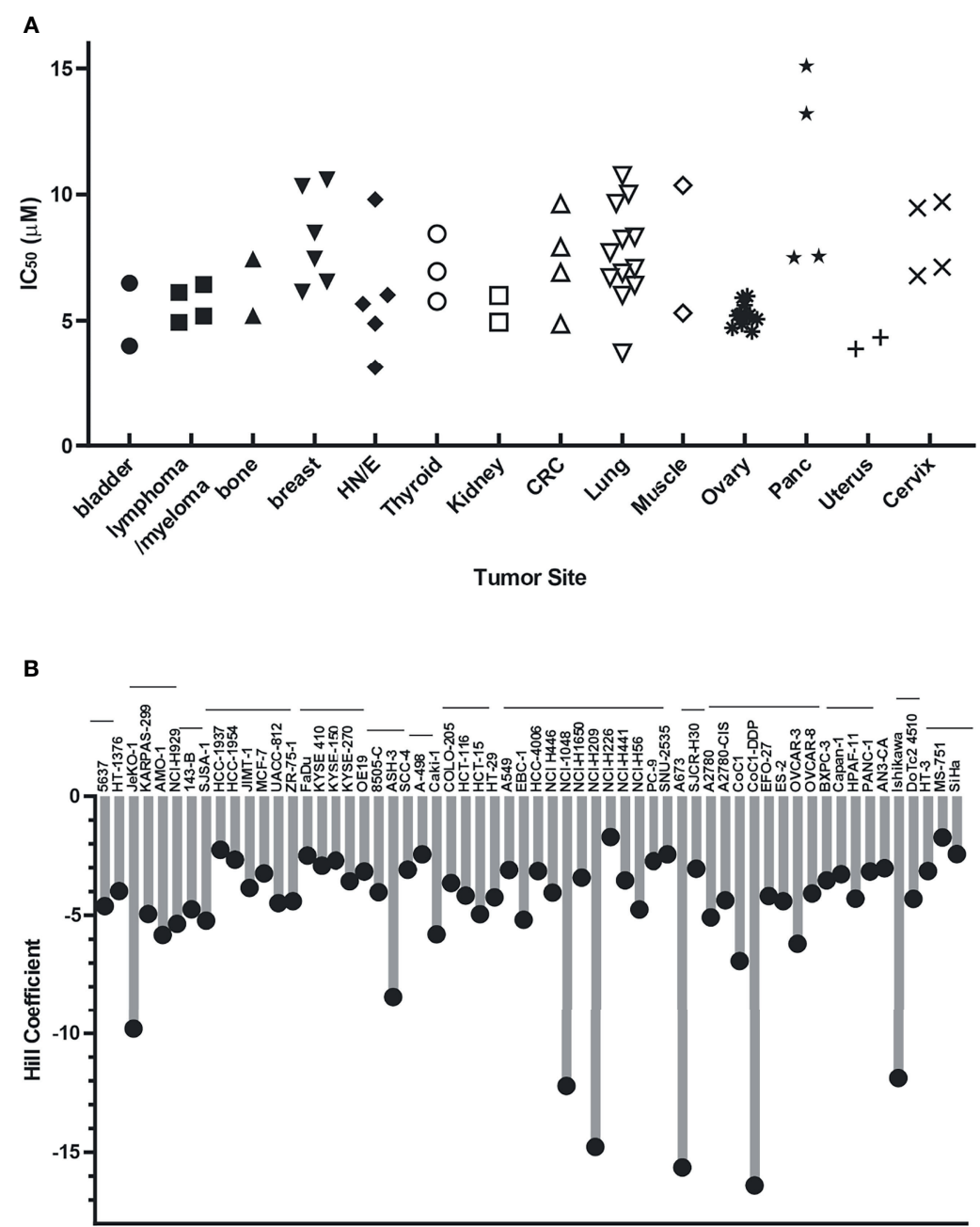

FIGURE 4 | Cellular activity of $\mathbf{3 2 9}$ in 60 cancer cell lines. Cell lines were treated with a 4-log range of replication protein A inhibitor (RPAi) $\mathbf{3 2 9}$ for 72 h. Cell viability was assessed using CellTiter-Glo luminescent viability assay. The data represent the average of triplicate treatments, and the data were fit using non-linear regression analysis to calculate cellular $I C_{50}$ s. (A) $I C_{50}$ results from each cell line grouped by tumor type. (B) Hill coefficients for individual cell lines. The horizontal lines above cell line names indicated the tumor sites in the order depicted in panel (A). 

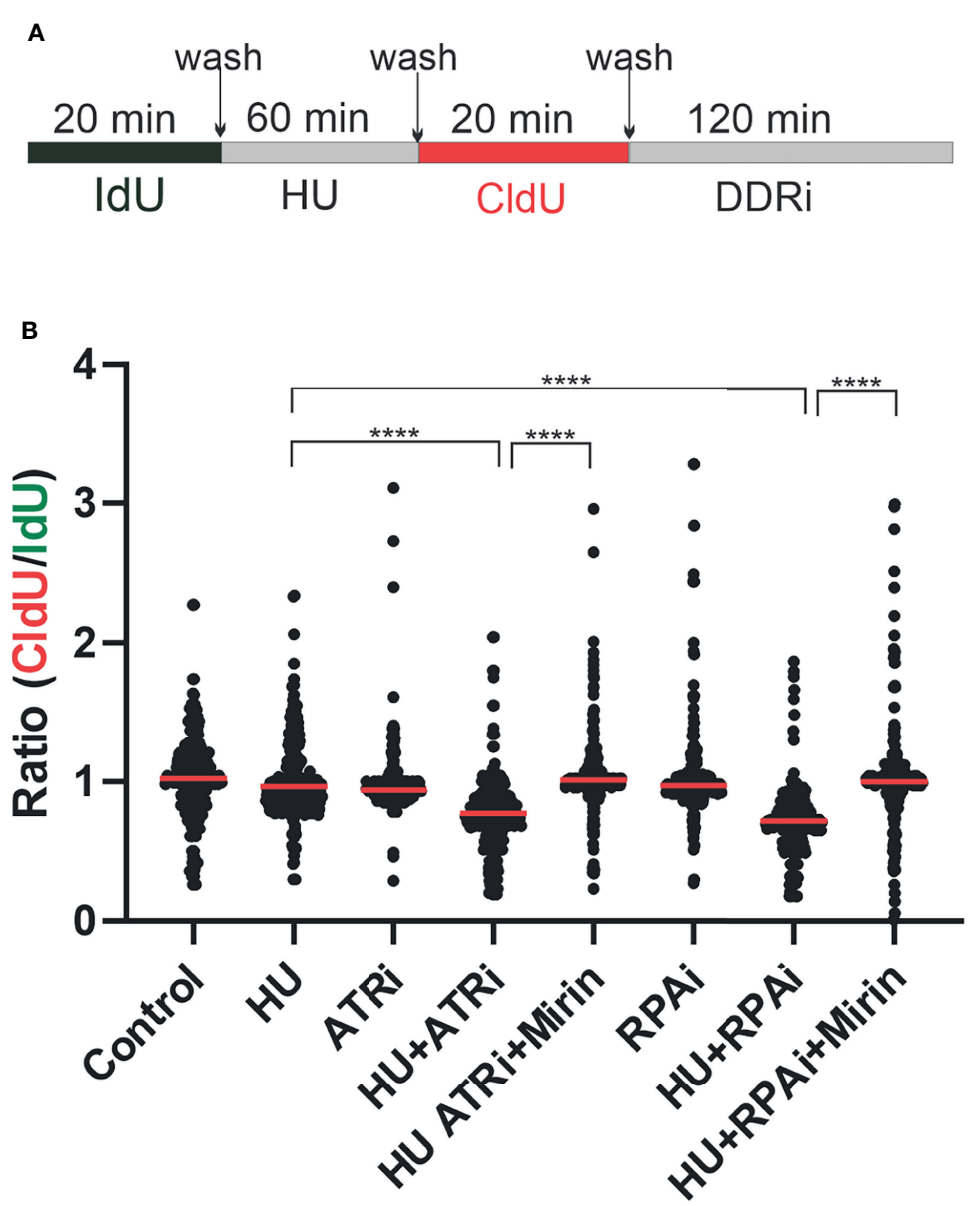

FIGURE 5 | Replication protein A inhibitor (RPAi) impact on replication fork dynamics. (A) Schematic depiction of experimental design. DNA was pulse-labeled with IdU for 20 min. After IdU removal, replication forks were stalled by the addition of $\mathrm{HU}$ or left to replicate with vehicle treatment. HU was removed, and replication was labeled with CldU. Following CldU, cells were treated with the DDRi or vehicle. (B) Quantification of results from DNA fiber analysis in H460 cells treated with the indicated agents. HU was used at a final concentration of $2.5 \mathrm{mM}$, the ATRi VE-822 at $2 \mu \mathrm{M}$, and the RPAi 329 at $50 \mu \mathrm{M}$. Data presented are combined from three individual experiments (100 fibers analyzed per experiment; 300 fibers total). Red bar indicates the median value of CldU/ldU. Data were analyzed by ANOVA with Bonferroni test for multiple comparisons $\left({ }^{\star \star \star \star} \mathrm{p}<0.0001\right)$.

Figure 5B. As expected, minimal effects were observed with ATRi or RPAi alone. However, in cells that received HU and then either ATRi or RPAi, a significant decrease in CldU/IdU signal was observed. These data suggest that the addition of DDRi after fork stalling by $\mathrm{HU}$ results in nascent strand degradation at stalled replication forks. Importantly, this decrease observed was reversible by mirin, an inhibitor that blocks degradation of the forks. Importantly, the effect of RPAi was similar to ATRi, as expected for targets in the same pathway. These data suggest that DDR checkpoint abrogation by ATRi or RPAi and a subsequent increase in the presence of unprotected ssDNA in S-phase result in replication fork instability and nascent strand degradation.

\section{Therapeutic Combinations}

Considering RPA's role in numerous DNA metabolic processes, we determined how inhibition of RPA impacts sensitivity to a variety of DNA-damaging chemotherapeutics that induce different types of damage. Interestingly, we observe synergy, as indicated by a $\mathrm{CI}<1$ at 0.5 or higher fraction of cells affected, with agents that cause replication stress, bulky lesions, and DNA double-strand breaks (Figure 6A), whereas no synergy was observed with paclitaxel, a non-DNA-damaging therapeutic. These results suggest that the cytotoxic effects of RPAis may be mediated by a broader effect on the DDR as opposed to suppression of individual replication and repair pathways. Considering these data, we suspected that RPA inhibition would synergize with other DDR-targeted therapeutics to block multiple pathways within the more broadly concerted DDR. We therefore assessed synergy of RPAis with a series of DDRtargeted agents that are currently in clinical trials (Figure 6B). The data demonstrate that modest synergy is observed with each agent in the H460 NSCLC cell model, with exception of the Wee1 inhibitor. Interestingly, we did observe modest synergy with the 

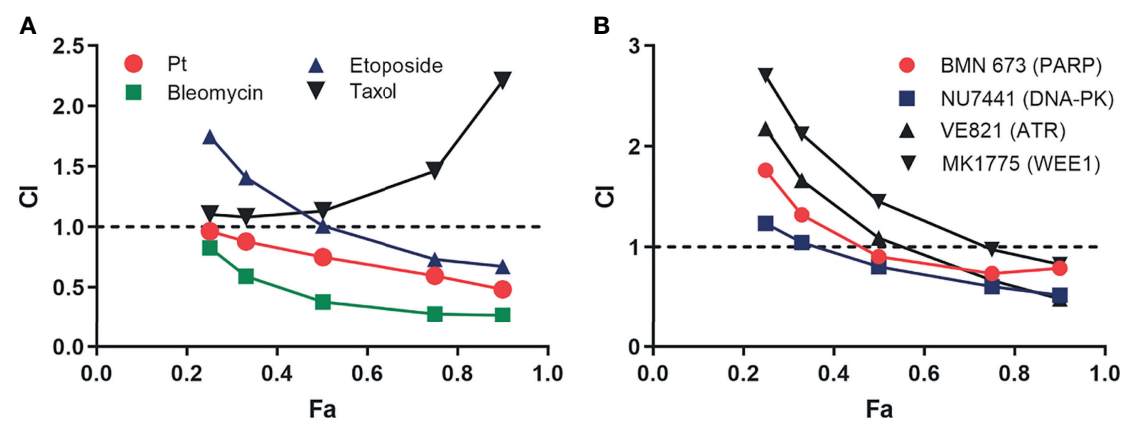

FIGURE 6 | Analysis of replication protein A inhibitor (RPAi) 329 combination treatment. (A) Chou-Talalay analysis of combination with chemotherapeutics. The combination index (CI) is plotted as a function of the fraction of cell affected (Fa) for each treatment combination of the 329. (B) Chou-Talalay analysis of combination with DDR-targeted agents as described in panel (A).

PARPi BMN637 in BRCA wild-type cells despite the relatively limited activity seen with single-agent PARPi in these cells. Not surprisingly, we have demonstrated a greater degree of synergy between RPAi and PARPi in BRCA1 null cells compared to BRCA wild-type cells (13). Interestingly, both ATR and DNAdependent protein kinase $(\mathrm{PK})$ inhibition were more effective when used in combination with RPAi treatment, suggesting that either inhibition of parallel pathways or sequential inhibition of a single pathway in the case of ATR contributes to enhanced increased anticancer activity. Weel inhibition however was antagonistic or additive with RPAi over the entire range of cells affected that places its activity downstream of RPA as expected.

\section{In Vivo Analyses}

Toward the goal to identify efficacious and safe RPAi 329 treatment regimens, we conducted single-agent screening in two lung cancer cell line-derived xenograft models. Predecessors to 329 and 2004, compounds 505 and 551, possessed modest in vivo activity (8). Having optimized cellular uptake and solubility via the addition of the propyl morpholino in 329 and 2004, we sought to determine how these modifications impact in vivo anticancer activity using two NSCLC models, A549 adenocarcinoma and H460 large cell carcinoma. Analysis of toxicity revealed that safe dosing could be achieved up to $200 \mathrm{mg} / \mathrm{kg}$ with no overt toxicity when formulated as a suspension in DMSO/Tween and no significant loss in body weight similar to predecessor compounds. Assessment of kidney function also showed no differences from vehicle controls (data not shown). Interestingly, we observed only modest single-agent anticancer activity in both models with differing dosing regimens of $\mathbf{3 2 9}$ and 2004 (14). That the modest in vivo activity is in fact similar to that observed for the $\mathbf{5 5 1}$ predecessor compound (8) was surprising in light of the increases in RPA inhibitory activity in vitro, increase in cellular uptakes (9), and dramatically increased activity in tissue culture models. This result suggested that the morpholino addition to $\mathbf{5 5 1}$ to generate $\mathbf{3 2 9}$ could be negatively impacting bioavailability. Analyses of intrinsic clearance and half-life were conducted in mouse and rat microsomes (Table 1). Here, 329 displayed favorable rates of clearance in mouse microsomes, $\sim 43 \mu \mathrm{l} / \mathrm{min} / \mathrm{mg}$. These values are less than the rate of 48 , which is considered rapid clearance. In rat microsomes, rates of $\sim 64$ were obtained for 329 and are less than the rapid rate of 71 . Half-lives of $20-40 \mathrm{~min}$ in mice and rats are also well within range for these in vitro clearance studies, suggesting that 329 was not limited by these parameters. Comparative analyses of PK parameters with 329 vs. 551 in the DMSO/Tween formulation revealed a significant reduction in AUC and $\mathrm{C}_{\max }$ with 329 compared to 551 (data not shown).

\section{Formulation of NERx 329}

With favorable potency, cellular activity, plasma stability, and a clear deficit in PK, we initiated a series of studies to assess and optimize a formulation of $\mathbf{3 2 9}$ for in vivo bioavailability. Here, 329 solubility was assessed in a series of additives, excipients, and co-solvents to identify initial favorable vehicles (Table 2). The surprising result was that $\mathbf{3 2 9}$ was highly soluble in $\mathrm{N}$ methylpyrilidone and displayed moderate solubility in oleic acid, propylene glycol, and PEG400. A series of different formulations were assessed. The final formulation consisted of polysorbate 80 , N-methyl-2-pyrrolidone (NMP), propylene glycol, and PEG 400 (+1.1 mol. eq. $\mathrm{HCl}$ added as $12 \mathrm{M} \mathrm{HCl})$,

TABLE 1 | Plasma stability and clearance.

\begin{tabular}{lll}
\hline & Mouse & \\
\hline $\mathrm{t}_{1 / 2}$ & $(\mathrm{~min})$ & 43.9 \\
CLint & $(\mathrm{uL} / \mathrm{min} / \mathrm{mg})$ & 31.7 \\
& Rat & \\
\hline $\mathrm{t}_{1 / 2}$ & $(\mathrm{~min})$ & 21.7 \\
CLint & $(\mathrm{uL} / \mathrm{min} / \mathrm{mg})$ & 63.8 \\
\hline
\end{tabular}

Analyses of intrinsic clearance and half-life were conducted in mouse and rat microsomes. 
TABLE 2 | Vehicle/excipient screen.

\section{Vehicle}

Solubility (mg/m I)

\section{Water}

$50 \mathrm{mM}$ sodium acetate $\mathrm{pH} 4$

$30 \%$ SBECD in water

Oleic acid

Cremophor EL

Labrasol

Propylene glycol

Polyethylene glycol 400

NMP

Polysorbate 80

Ethanol

A series of additives, excipients, and co-solvents were assessed in basic formulation studies to optimize bioavailability.

and 329 was soluble up to $20 \mathrm{mg} / \mathrm{ml}$, and 10-fold dilution in PBS was well dispersed with minimal precipitation. Fourteen-day stability assessments were conducted with this formulation, and the data demonstrate that $\mathbf{3 2 9}$ is very stable up to $40^{\circ} \mathrm{C}$, while degradation was observed with extended incubations at $60^{\circ}$ $\mathrm{C}$ (Figure 7A) Calculation of the T90, time to reduce active agent to $90 \%$, was calculated for each temperature and extrapolated to $5^{\circ} \mathrm{C}$ where 329 is predicted to be stable for over 5 years and at room temperature for over 3 months (Table 3 ). Based on these data, the lead formulation is deemed stable for preparation and storage of $\mathbf{3 2 9}$ at room temperature to support in vivo studies.

\section{Pharmacokinetic Analysis of 329 in Optimized Formulation}

$\mathrm{PK}$ parameters were assessed in a series of studies in immunocompetent mice both IV and IP (Figure 7B and Table 4). Data demonstrate that IP delivery with the new formulation at $200 \mathrm{mg} / \mathrm{kg}$ is enhanced, and results showed significantly improved values including $\mathrm{C}_{\max }, \mathrm{T}_{\max }$, and AUC. The half-life was also well within acceptable range $(9 \mathrm{~h})$. However, dosing at $200 \mathrm{mg} / \mathrm{kg}$ in the new formulation resulted in increased toxicity. Considering the increased exposure as a result of drastically improved PK parameters, increased toxicity is not surprising. Interestingly, reducing the dose to $20 \mathrm{mg} / \mathrm{kg}$ results in a similar $\mathrm{C}_{\max }$ but reduced $\mathrm{AUC}$ as a result of $\mathrm{T}_{1 / 2}$ and $\mathrm{T}_{\max }$ differences. IV dosing was performed to allow calculation of absolute bioavailability of 0.84 at $20 \mathrm{mg} / \mathrm{kg}$.
TABLE 3 | Stability analysis.

\begin{tabular}{lc}
\hline Condition & t90* (days) \\
\hline $60^{\circ} \mathrm{C}$ & 3.2 \\
$40^{\circ} \mathrm{C}$ & 26 \\
$25^{\circ} \mathrm{C}$ & 140 \\
$5^{\circ} \mathrm{C}$ (extrapolated) & 2100 \\
\hline
\end{tabular}

The chemical stability of $10 \mathrm{mg} / \mathrm{ml}$ of NERx 329 in lead formulation was assessed at $25^{\circ} \mathrm{C}$, $40^{\circ} \mathrm{C}$, and $60^{\circ} \mathrm{C}$ for a period of 2 weeks.

\section{In Vivo Analysis of 329 in Optimized Formulation in Non-Small Cell Lung Cancer (NSCLC) Xenograft Models}

The long-term goal is to move toward efficacious and safe combination therapies that include RPA inhibition. Predecessor molecules to 329 and 2004, compounds 505 and 551, possessed modest in vivo activity (8). With optimized formulation for 329 and favorable PK parameters, we proceeded to in vivo single-agent efficacy studies in H460 large cell carcinoma and A549 adenocarcinoma xenografts. Tumor cells were implanted in NOD/SCID mice that were randomized and treated with vehicle or $20 \mathrm{mg} / \mathrm{kg}$ of 329. Considering the rapid growth kinetics of $\mathrm{H} 460$, we administered 329 at $20 \mathrm{mg} / \mathrm{kg}$ daily for 5 days, with 2 days off, repeated 3 times. With this dosing strategy, a decrease in tumor volume was observed starting at day 17 (Figure 8A). Importantly, previous studies with 329 in a suboptimal formulation resulted in similar tumor growth delay, but with dosing completed at $200 \mathrm{mg} / \mathrm{kg}$ (data not shown). This suggests that the newly identified formulation results in single-agent activity as predicted, but that anticancer activity can be achieved using one-tenth the amount of drug. This study clearly shows that a dynamic range is possible and further demonstrates a dose response to 329 in vivo, particularly profound as tumor size slightly increases when animals had 2 days of recovery from drug dosing, followed by an immediate tumor reduction after dosing was resumed. Similar studies were conducted in A549 xenograft model, with IP dosing as indicated in the figure, at $40 \mathrm{mg} / \mathrm{kg}$. The results demonstrate that mice in the treatment arm display a significant reduction in tumor growth (Figure 8B). This result was confirmed in the analysis of terminal tumor weight that revealed significant smaller tumors in 329-treated mice (Figure 8C). Together, these data demonstrate the utility of RPAi in treating lung cancer.
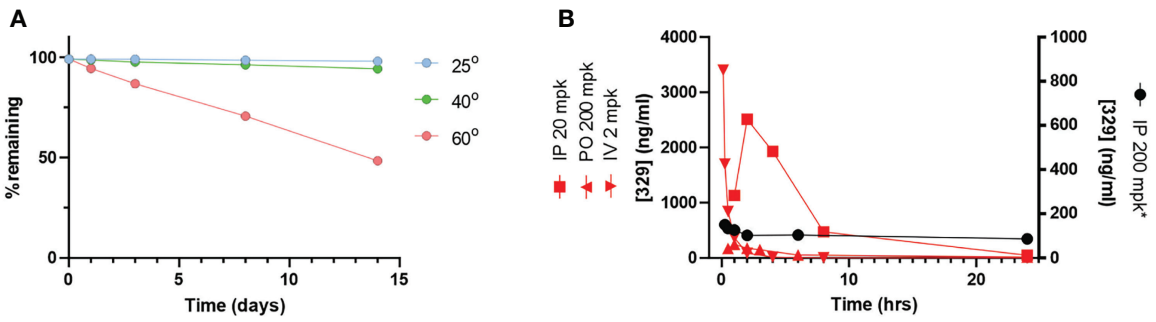

FIGURE 7 | The $\mathbf{3 2 9}$ in vivo analysis. (A) Stability analysis. Compound stability was assessed over a 14-day time period at varying temperatures as indicated. (B) Pharmacokinetic analysis. Time course of drug plasma concentration over $24 \mathrm{~h}$ following drug administration as indicated in legend. 
TABLE 4 | Pharmacokinetic analysis of $\mathbf{3 2 9}$

\begin{tabular}{|c|c|c|c|c|c|}
\hline Parameter & Unit & & Value & & \\
\hline Route/Vehicle/dose & $\mathrm{mg} / \mathrm{kg}$ & |IP/DMSO/200 & IP/NMP/200 & IP/NMP/20 & IV/NMP/2 \\
\hline Lambda_z & $1 / h$ & 0.02 & 0.07 & 0.11 & 0.21 \\
\hline $\mathrm{t} 1 / 2$ & $\mathrm{~h}$ & 30.86 & 9.311 & 6.30 & 3.28 \\
\hline Tmax & $\mathrm{h}$ & 0.25 & 8.00 & 2.00 & 0.50 \\
\hline Cmax & $\mathrm{ng} / \mathrm{ml}$ & 92.11 & 2913.57 & 2511.65 & 840.89 \\
\hline Clast_obs/Cmax & & 0.305 & 0.315 & 0.002 & 0.003 \\
\hline AUC 0-t & $\mathrm{ng} / \mathrm{ml}^{\star} \mathrm{h}$ & 967.99 & 52010.59 & 16425.20 & 1396.47 \\
\hline AUC 0-inf_obs & $\mathrm{ng} / \mathrm{ml}^{\star} \mathrm{h}$ & 2218.00 & 64333.98 & 16474.36 & 1407.62 \\
\hline AUC 0-t/0-inf_obs & & 0.44 & 0.81 & 1.00 & 0.99 \\
\hline AUMC 0-inf_obs & $\mathrm{ng} / \mathrm{ml}^{\star} \mathrm{h} \wedge 2$ & 95023.52 & 947545.56 & 98489.24 & 1897.83 \\
\hline MRT 0-inf_obs & $\mathrm{h}$ & 42.84 & 14.73 & 5.981 & 1.35 \\
\hline Vz/F_obs & $(\mathrm{mg} / \mathrm{kg}) /(\mathrm{ng} / \mathrm{ml})$ & 4.015 & 0.172 & 0.011 & 0.007 \\
\hline $\mathrm{Cl} / \mathrm{F} \_$obs & $(\mathrm{mg} / \mathrm{kg}) /(\mathrm{ng} / \mathrm{ml}) / \mathrm{h}$ & 0.0902 & 0.0128 & 0.0012 & 0.0014 \\
\hline
\end{tabular}

Drug formulated in the optimal NMP solution was assessed for IV or IP delivery at varying doses, as indicated.

Further analysis including dosing and schedule is predicted to achieve maximal anticancer activity.

\section{DISCUSSION}

The DDR is actively being pursued for cancer therapy, with phase I results being recently reported for ATRis (15). The vast majority of individual targets being developed in the DDR space are kinases, largely a function of the advances made over the past decade on developing kinase-targeted agents in the growth signaling pathways (16). Kinases, however, represent a minority of the protein components in the DDR pathway and larger replication, repair, and recombination pathways $[8 ; 25]$. There are myriad opportunities to impede the DDR via non-kinase targeted agents $(10,17,18)$. The DDR pathway is initiated by sensing DNA discontinuities, damage, or DNA structures via DNA binding modules associated with each kinase DNA-PK, ATM, and ATR. We have targeted these unique protein-DNA interactions with small molecules to first elucidate specific mechanisms of DDR activation that can be used to guide the development of cancer therapeutics (19-23). RPA is a complex target as a function of its roles in multiple DNA metabolic and catabolic pathways (24). Two classes of RPAis were initially discovered: (i) covalent RPA modification agents and (ii) reversible inhibitors that target the oligonucleotide/oligosaccharide binding folds (OB-folds) responsible for the RPA-DNA interaction (3). In this report using optimized reversible RPAis, we demonstrate single-agent in vivo activity and synergy in combination with traditional and DDRtargeted therapy. Furthermore, we probed the putative mechanism of RPAi's anticancer activity.

PARPi therapy has now been approved in 4 different solid tumors, with prostate and pancreatic joining ovarian and breast in the list of approved indications. Recent evidence on the mechanism of PARPi suggests that ssDNA and specifically lagging strand gaps contribute to PARP efficacy (25). If this mechanism is relevant, one could envision that BRCA wild-type cells would be sensitized to PARPi if the DDR was chemically inhibited. Our finding of synergy as measured by Chou-Talalay combination index analysis supports this basic finding and extends to our recent analyses in BRCA1-deficient cells that show that BRCA1-deficient cells are hypersensitive to RPAi compared to BRCA-complemented cells (26). The observation of synergy in BRCA wild-type cells suggests that RPA inhibition could impair homologous recombination repair (HRR) to create an HR phenotype that increases the potency of PARPi. The impact on HR could be in addition to the effect on the DDR. This result is consistent with our observation of synergy with both ATR and DNA-PK inhibition that can be explained by RPAi impacts on individual and parallel pathways or cross talk between the DDR signaling events. An alternative hypothesis is that another aspect of RPA involvement could explain the synergy, including an alteration in replication fork stability and restart. This is supported by the single-molecule studies that the effects of RPAi on replication dynamics are similar to those of ATRi effects that remain consistent with the dependent nature of ATR on RPA-DNA binding activity in signaling replication fork stress. It is interesting that ATR activity is impacted by ATM as well based on recent studies in both in vitro models and patient responses in clinical trial data. This suggests that the cross talk between the three arms of the DDR, DNA-PK, ATM, and ATR, is advantageous if not necessary for responding to replication stress or DNA damage. The ability to block the binding of RPA to ssDNA can induce differential effects depending on the RPA requirement for each pathway. For instance, the amount of RPA needed for nucleotide excision repair (NER) of cisplatintreated cells is anticipated to be very low based on the cellular levels of cisplatin damage. Accordingly, our observation that RPAi does not impact NER-catalyzed repair is not surprising. Similarly, in normal, unperturbed DNA replication, RPAi has minimal effects on our initial assessment of replication dynamics; however, when fork stalling is induced by HU, a dramatic effect of RPAi is observed, consistent with the increase in the amount of RPA needed to address the replication stress and the limited RPA available as a function of the inhibitor.

The model of RPA threshold is consistent with our analysis of RPAi cellular activity and the tumor agnostic mechanism of action. Also consistent with these data are previous findings that RPA expression has been described as a prognostic and predictive biomarker in a small number of studies (27-29). 

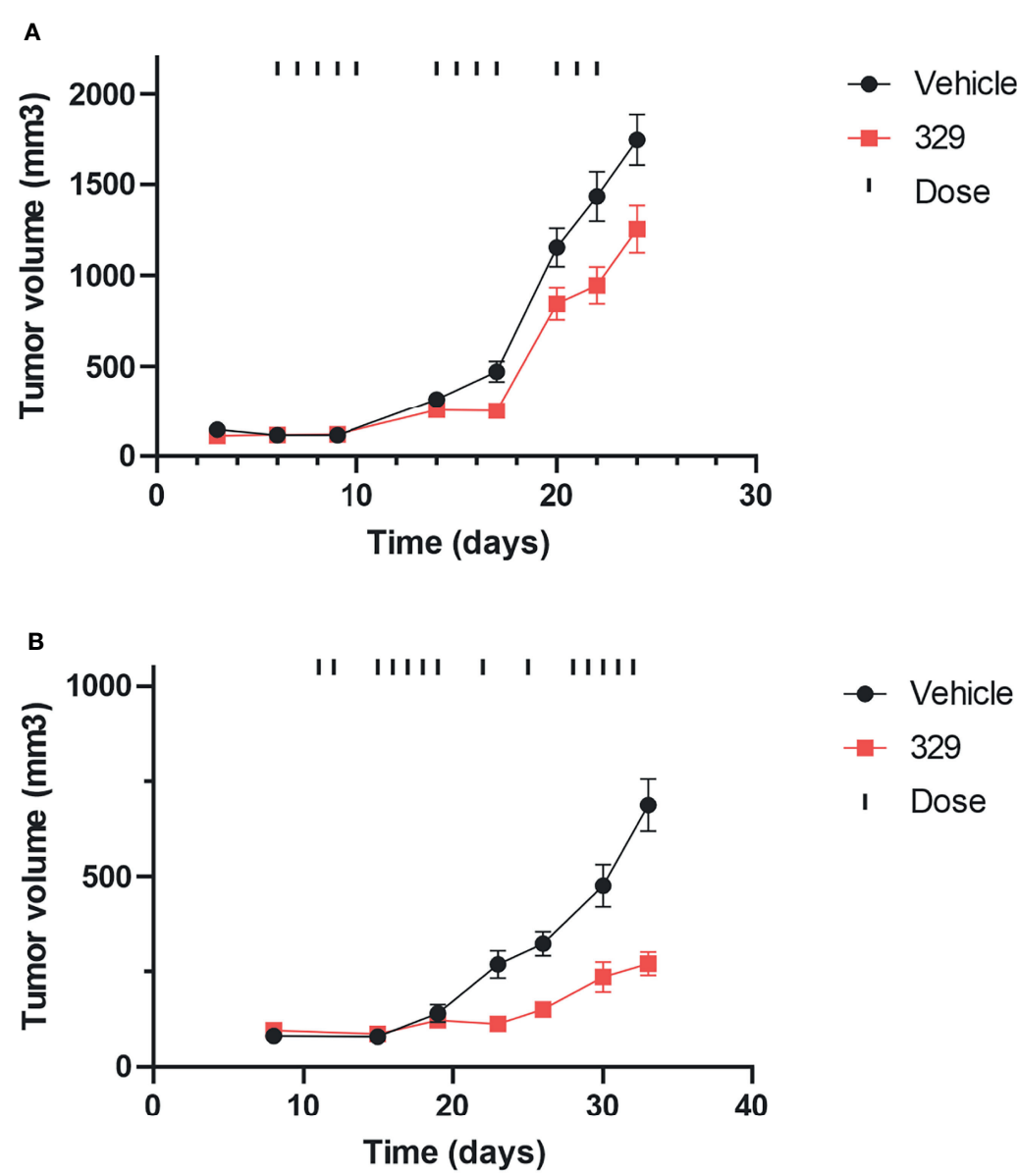

Vehicle

329

I Dose

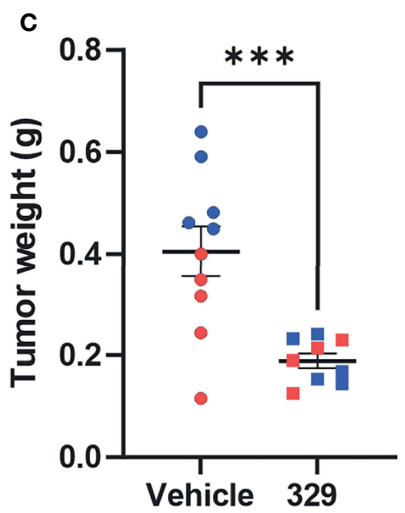

FIGURE 8 | In vivo analysis of anticancer activity of 329. (A) Anticancer activity was assessed in human H460 NCSLC tumor xenografts in NOD/SCID mice. Mice were implanted subcutaneously on day 1 with H460 NSCLC cells, tumors were measured by calipers, and mice assigned randomly to treatment arms. Treatment with $\mathbf{3 2 9}$ was initialized at day 6 and administered via intraperitoneal injection (IP) once daily (20 mg/kg), as indicated (I). Tumor volumes were completed with caliper measurement biweekly. (B) A549 cells were implanted subcutaneously, mice were randomized, and treatment with $\mathbf{3 2 9}$ was initiated at day 11 via IP (40 mg/kg) and treated once daily as indicated (|). (C) Tumor weight from A549 cells was determined on day 32 . Statistically significance differences from vehicle-treated tumors are indicated by the asterisk ${ }^{\star} \mathrm{p}<0.05 ;{ }^{\star \star *} \mathrm{p}<0.01$.

Our retrospective analysis of NSCLC confirms and extends these studies to demonstrate that RPA expression levels can be both prognostic and predictive in smoking-associated lung cancers. Its role in the DDR is likely critical to respond and protect from the myriad of genetic insults stemming from carcinogen exposure. It is therefore interesting to speculate that RPA expression or activity may also be predictive of response to other DDRtargeted therapeutics. 
Recent advances in kinase-targeted agents and immunooncology (IO) therapy have changed many treatment paradigms for lung cancer. The discovery of driver mutations and chromosomal rearrangements in NSCLC has resulted in the availability of molecularly targeted agents for $40 \%$ of NSCLC (30), including EGFR tyrosine kinase inhibitors (TKIs) and ALK TKIs. Despite these targeted therapeutic advances, the clinical reality is that over $60 \%$ of NSCLC patients will continue to receive the common chemotherapy, Pt-based agent, as part of their therapy. Lung epithelial cells are exposed to a variety of carcinogens that can be dramatically increased in cigarette smoke exposure and likely contribute to the high mutation burden observed in smoking-related cancers. It stands to reason that lung epithelium would have a robust DNA repair capacity to counter the DNA damage elicited by cigarette smoking, and early research demonstrated the importance of DNA repair in lung carcinogenesis $(31,32)$. This repair capacity can explain the rapid resistance to cancer therapeutic modalities that induce DNA damage including two frequently used Pt-based agents, cisplatin and carboplatin, and ionizing radiation. Recent advances in our understanding of how cells, both normal and cancerous, respond to DNA damage stress has identified a number of unique vulnerabilities that can be exploited for effective therapy to treat cancer. Our retrospective and cellular data strongly suggest that RPA plays an important role in treating this disease. This premise is supported by the clear single-agent anticancer activity observed with our newly formulated RPAi and combined suggests that inhibition of RPA will have a significant impact on cancer therapy in this difficult to treat disease.

\section{REFERENCES}

1. Lord CJ, Tutt AN, Ashworth A. Synthetic Lethality and Cancer Therapy: Lessons Learned From the Development of PARP Inhibitors. Annu Rev Med (2015) 66:455-70. doi: 10.1146/annurev-med-050913-022545

2. Chabanon RM, Rouanne M, Lord CJ, Soria JC, Pasero P, Postel-Vinay S. Targeting the DNA Damage Response in Immuno-Oncology: Developments and Opportunities. Nat Rev Cancer (2021) 21:701-17. doi: 10.1038/s41568021-00386-6

3. Gavande NS, VanderVere-Carozza PS, Hinshaw HD, Jalal SI, Sears CR, Pawelczak KS, et al. DNA Repair Targeted Therapy: The Past or Future of Cancer Treatment? Pharmacol Ther (2016) 160:65-83. doi: 10.1016/ j.pharmthera.2016.02.003

4. Toledo LI, Altmeyer M, Rask MB, Lukas C, Larsen DH, Povlsen LK, et al. ATR Prohibits Replication Catastrophe by Preventing Global Exhaustion of RPA. Cell (2013) 155:1088-103. doi: 10.1016/j.cell.2013.10.043

5. Toledo L, Neelsen KJ, Lukas J. Replication Catastrophe: When a Checkpoint Fails Because of Exhaustion. Mol Cell (2017) 66:735-49. doi: 10.1016/ j.molcel.2017.05.001

6. Shuck SC, Turchi JJ. Targeted Inhibition of Replication Protein A Reveals Cytotoxic Activity, Synergy With Chemotherapeutic DNA-Damaging Agents, and Insight Into Cellular Function. Cancer Res (2010) 70:3189-98. doi: 10.1158/0008-5472.CAN-09-3422

7. Anciano Granadillo VJ, Earley JN, Shuck SC, Georgiadis MM, Fitch RW, Turchi JJ. Targeting the OB-Folds of Replication Protein A With Small Molecules. J Nucleic Acids (2010) 2010:304035. doi: 10.4061/2010/304035

8. Mishra AK, Dormi SS, Turchi AM, Woods DS, Turchi JJ. Chemical Inhibitor Targeting the Replication Protein A-DNA Interaction Increases the Efficacy

\section{DATA AVAILABILITY STATEMENT}

The original contributions presented in the study are included in the article/supplementary material. Further inquiries can be directed to the corresponding authors.

\section{ETHICS STATEMENT}

The animal study was reviewed and approved by IACUCIndiana University.

\section{AUTHOR CONTRIBUTIONS}

PV-C contributed cellular studies. NG contributed chemical synthesis. EE, JH, and SP contributed DNA fiber analysis data. All authors contributed to the article and approved the submitted version.

\section{FUNDING}

This work was supported by NIH grant R01 CA257430 and the Tom and Julie Wood Family Foundation (J.J.T.). Additional studies were supported by NIH grant RO1CA229535 (S.M.P.), NICHD P50HD090215 (K.E.P), P30CA082709 awarded to the Indiana University Simon Comprehensive Cancer Center (K.E.P), and the Indiana University Grand Challenge-Precision Health Initiative (K.E.P). of Pt-Based Chemotherapy in Lung and Ovarian Cancer. Biochem Pharmacol (2015) 93:25-33. doi: 10.1016/j.bcp.2014.10.013

9. Gavande NS, VanderVere-Carozza PS, Pawelczak KS, Vernon TL, Jordan MR, Turchi JJ. Structure-Guided Optimization of Replication Protein A (RPA)-DNA Interaction Inhibitors. ACS Med Chem Lett (2020) 11:111824. doi: 10.1021/acsmedchemlett.9b00440

10. Gavande NS, VanderVere-Carozza PS, Pawelczak KS, Mendoza-Munoz P, Vernon TL, Hanakahi LA, et al. Discovery and Development of Novel DNAPK Inhibitors by Targeting the Unique Ku-DNA Interaction. Nucleic Acids Res (2020) 48:11536-50. doi: 10.1093/nar/gkaa934

11. Nieminuszczy J, Schwab RA, Niedzwiedz W. The DNA Fibre Technique Tracking Helicases at Work. Methods (2016) 108:92-8. doi: 10.1016/j.ymeth. 2016.04.019

12. Petermann E, Orta ML, Issaeva N, Schultz N, Helleday T. HydroxyureaStalled Replication Forks Become Progressively Inactivated and Require Two Different RAD51-Mediated Pathways for Restart and Repair. Mol Cell (2010) 37:492-502. doi: 10.1016/j.molcel.2010.01.021

13. Cong K, Peng M, Kousholt AN, Lee WTC, Lee S, Nayak S, et al. Replication Gaps are a Key Determinant of PARP Inhibitor Synthetic Lethality With BRCA Deficiency. Mol Cell (2021) 81:3128-44. doi: 10.1016/j.molcel.2021. 06.011

14. VanderVere-Carozza P, Pawelczak KS, Gavande NS, Jalal S, Pollok KE, Ekinci E, et al. Chemical Exhaustion of RPA in Cancer Treatment. BioRxIV (2020). doi: $10.1101 / 2020.11 .30 .404640$

15. Yap TA, Krebs MG, Postel-Vinay S, El-Khouiery A, Soria JC, Lopez J, et al. Ceralasertib (AZD6738), an Oral ATR Kinase Inhibitor, in Combination With Carboplatin in Patients With Advanced Solid Tumors: A Phase I Study. Clin Cancer Res (2021). doi: 10.1158/1078-0432.CCR-21-1032 
16. Tan CS, Kumarakulasinghe NB, Huang YQ, Ang YLE, Choo JR, Goh BC, et al. Third Generation EGFR TKIs: Current Data and Future Directions. Mol Cancer (2018) 17:29. doi: 10.1186/s12943-018-0778-0

17. Arora S, Heyza J, Zhang H, Kalman-Maltese V, Tillison K, Floyd AM, et al. Identification of Small Molecule Inhibitors of ERCC1-XPF That Inhibit DNA Repair and Potentiate Cisplatin Efficacy in Cancer Cells. Oncotarget (2016) 7:75104-17. doi: 10.18632/oncotarget.12072

18. Exell JC, Thompson MJ, Finger LD, Shaw SJ, Debreczeni J, Ward TA, et al. Cellularly Active N-Hydroxyurea FEN1 Inhibitors Block Substrate Entry to the Active Site. Nat Chem Biol (2016) 12:815-21. doi: 10.1038/ nchembio. 2148

19. Gavande NS, VanderVere-Carozza P, Mishra AK, Vernon TL, Pawelczak KS, Turchi JJ. Design and Structure-Guided Development of Novel Inhibitors of the Xeroderma Pigmentosum Group A (XPA) Protein-DNA Interaction. J Med Chem (2017) 60:8055-70. doi: 10.1021/acs.jmedchem.7b00780

20. Gavande NS, VanderVere-Carozza PS, Pawelczak KS, Vernon TL, Jordan MR, Turchi JJ. Structure-Guided Optimization of Replication Protein A (RPA)DNA Interaction Inhibitors. ACS Med Chem Lett (2020). doi: 10.1021/ acsmedchemlett.9b00440

21. Pawelczak KS, Gavande NS, VanderVere-Carozza PS, Turchi JJ. Modulating DNA Repair Pathways to Improve Precision Genome Engineering. ACS Chem Biol (2018) 13:389-96. doi: 10.1021/acschembio.7b00777

22. Neher TM, Shuck SC, Liu J, Zhang JT, Turchi JJ. Identification of Novel Small Molecule Inhibitors of the XPA Protein Using in Silico Based Screening. ACS Chem Biol (2010) 5:953-65. doi: 10.1021/cb1000444

23. Neher TM, Bodenmiller D, Fitch RW, Jalal SI, Turchi JJ. Novel Irreversible Small Molecule Inhibitors of Replication Protein A Display Single-Agent Activity and Synergize With Cisplatin. Mol Cancer Ther (2011) 10:1796-806. doi: 10.1158/1535-7163.MCT-11-0303

24. Haring SJ, Mason AC, Binz SK, Wold MS. Cellular Functions of Human RPA1. Multiple Roles of Domains in Replication, Repair, and Checkpoints. J Biol Chem (2008) 283:19095-111. doi: 10.1074/jbc.M800881200

25. Hanzlikova H, Kalasova I, Demin AA, Pennicott LE, Cihlarova Z, Caldecott KW. The Importance of Poly(ADP-Ribose) Polymerase as a Sensor of Unligated Okazaki Fragments During DNA Replication. Mol Cell (2018) 71:319-31. doi: 10.1016/j.molcel.2018.06.004

26. Cong K, Peng M, Kousholt AN, Lee WTC, Lee S, Nayak S, et al. Replication Gaps are a Key Determinant of PARP Inhibitor Synthetic Lethality With BRCA Deficiency. Mol Cell (2021) 81:3227. doi: 10.1016/ j.molcel.2021.07.015

27. Levidou G, Gakiopoulou H, Kavantzas N, Saetta AA, Karlou M, Pavlopoulos P, et al. Prognostic Significance of Replication Protein A (RPA) Expression
Levels in Bladder Urothelial Carcinoma. BJU Int (2011) 108:E59-65. doi: 10.1111/j.1464-410X.2010.09828.x

28. Levidou G, Ventouri K, Nonni A, Gakiopoulou H, Bamias A, Sotiropoulou M, et al. Replication Protein A in Nonearly Ovarian Adenocarcinomas: Correlation With MCM-2, MCM-5, Ki-67 Index and Prognostic Significance. Int J Gynecol Pathol (2012) 31:319-27. doi: 10.1097/PGP.0b013e31823ef92e

29. Givalos N, Gakiopoulou H, Skliri M, Bousboukea K, Konstantinidou AE, Korkolopoulou P, et al. Replication Protein A is an Independent Prognostic Indicator With Potential Therapeutic Implications in Colon Cancer. Mod Pathol (2007) 20:159-66. doi: 10.1038/modpathol.3800719

30. Simon GR. Individualizing Chemotherapy for non-Small Cell Lung Cancer (NSCLC) in the Adjuvant and Advanced Setting: Current Status and Future Directions. Curr Treat Options Oncol (2008) 9:300-12. doi: 10.1007/s11864008-0075-Z

31. Shen H, Spitz MR, Qiao Y, Guo Z, Wang LE, Bosken CH, et al. Smoking, DNA Repair Capacity and Risk of Nonsmall Cell Lung Cancer. Int J Cancer (2003) 107:84-8. doi: 10.1002/ijc.11346

32. Wei Q, Cheng L, Amos CI, Wang LE, Guo Z, Hong WK, et al. Repair of Tobacco Carcinogen-Induced DNA Adducts and Lung Cancer Risk: A Molecular Epidemiologic Study. J Natl Cancer Inst (2000) 92:1764-72. doi: $10.1093 /$ jnci/92.21.1764

Conflict of Interest: Author JT is a shareholder and founder and KP is a shareholder and employed by NERx BioSciences.

The remaining authors declare that the research was conducted in the absence of any commercial or financial relationships that could be construed as a potential conflict of interest.

Publisher's Note: All claims expressed in this article are solely those of the authors and do not necessarily represent those of their affiliated organizations, or those of the publisher, the editors and the reviewers. Any product that may be evaluated in this article, or claim that may be made by its manufacturer, is not guaranteed or endorsed by the publisher.

Copyright (C) 2022 VanderVere-Carozza, Gavande, Jalal, Pollok, Ekinci, Heyza, Patrick, Masters, Turchi and Pawelczak. This is an open-access article distributed under the terms of the Creative Commons Attribution License (CC BY). The use, distribution or reproduction in other forums is permitted, provided the original author(s) and the copyright owner(s) are credited and that the original publication in this journal is cited, in accordance with accepted academic practice. No use, distribution or reproduction is permitted which does not comply with these terms. 